\title{
Privatização e financeirização de infraestruturas no Brasil: agentes e estratégias rentistas no pós-crise mundial de 2008
}

\author{
Privatization and financialization of infrastructures in Brazil: \\ agents and rentier strategies after global financial crisis of \\ 2008
}

Beatriz Rufino [a] $[$ iD

[a] Universidade de São Paulo (USP), Faculdade de Arquitetura e Urbanismo (FAUUSP), São Paulo, SP, Brasil

Como citar: Rufino, B. Privatização e financeirização de infraestruturas no Brasil: agentes e estratégias rentistas no pós-crise mundial de 2008. urbe. Revista Brasileira de Gestão Urbana, v. 13, e20200410.

https://doi.org/10.1590/2175-3369.013.e20200410

\section{Resumo}

\begin{abstract}
A produção de infraestruturas no Brasil vem passando por importantes transformações desde os anos 1990, articulando-se com o alinhamento do país a uma agenda neoliberal. A adoção de políticas anticíclicas como resposta à crise de 2008 expande e torna mais complexa a natureza desses processos. Na compreensão das condições particulares engendradas nesse momento, destacam-se o papel histórico do BNDES na condução dos processos de privatização e o crescente poder econômico e político das grandes empreiteiras nacionais. Partindo de um diálogo com o debate internacional sobre privatização e financeirização das infraestruturas, procuramos compreender o caso brasileiro, problematizando a crescente centralidade de uma lógica rentista. 0 artigo desenvolve-se por meio da análise dos arranjos institucionais, dos agentes dominantes e das estratégias de acumulação, considerando a sistematização e interpretação crítica da bibliografia, documentos e dados referentes à transformação do setor.
\end{abstract}

Palavras-chave: Parcerias Público-Privadas. Finanças. Renda.

\section{Abstract}

Infrastructure production in Brazil has undergone important transformations since the 1990s, articulating itself with the country's alignment with a neoliberal agenda. The adoption of countercyclical policies in response to the 2008 crisis, expands and makes the nature of these processes even more complex. The historical role of the BNDES in conducting the privatization processes and the growing economic and political power of the major national contractors are taking is central elements to understand this process. Discussing with the international debate about privatization and financialization of infrastructures, we seek to understand the Brazilian case in order to problematize the increase centrality of rent accumulation. The article is developed through the analysis of institutional arrangements, dominant 
agents and accumulation strategies, considering the systematization and critical interpretation of the bibliography, documents and data referring to the transformation of the sector.

Keywords: Public-private partnerships. Finance. Rent.

\section{Introdução'}

O avanço dos processos de privatização e financeirização tem afetado a forma como as infraestruturas são produzidas e operadas, levando à priorização de projetos com maior rentabilidade e menores riscos e direcionando os investimentos para determinados setores e localizações, com ampliação do protagonismo de investimentos urbanos. As infraestruturas, compreendidas como condições gerais da valorização capitalista e da reprodução social, projetam-se na contemporaneidade como importante setor de negócios.

A disseminação mundial desses processos, ao mesmo tempo que tende a homogeneizar regulações, instrumentos e estratégias, parece ser mediada por condições específicas, tais como as condições particulares de inserção econômica dos diferentes países e os interesses das elites nacionais, explicando distintas trajetórias.

No contexto latino-americano, a financeirização tem sido amplamente mobilizada na análise das dinâmicas imobiliárias, tendo pouco relevo na interpretação das transformações na produção das infraestruturas. $\mathrm{O}$ crescimento econômico acelerado, durante parte do século XXI no continente, legitimou e viabilizou uma importante agenda de investimentos em infraestrutura, implementados em grande parte dos casos por importante participação de governos progressistas, mas em convergência com as agendas de privatização. Esses processos, que têm sido reconhecidos por alguns autores como um "novo desenvolvimentismo" (Bresser-Pereira, 2007), articulam-se em forte medida aos processos sistêmicos de financeirização da economia.

Kaltenbrunner \& Painceira (2018, p. 34) destacam o crescente número de estudos que documentam mudanças nas práticas e relações financeiras dos agentes econômicos capitalistas, dos países periféricos, similares às analisadas nas economias capitalistas centrais, entretanto, observam uma natureza específica dessa financeirização. Rocha (2013), ao analisar a crescente disseminação do conceito de dominância financeira, procura enfatizar suas limitações na medida em que essa dominância se caracteriza como um regime de acumulação, onde se pressupõe a disseminação de mecanismos de "regulação",

[...] que tendem a reproduzir a lógica já definida pelo movimento das economias centrais, resultando em análises que negligenciam os mecanismos de defesa das classes dominantes em seus espaços nacionais e as adaptações das economias nacionais às novas mudanças provocadas na divisão internacional do trabalho (Rocha, 2013, p. 34).

A produção de infraestruturas no Brasil vem passando por importantes transformações desde os anos 1990, articulando-se com o alinhamento do país a uma agenda neoliberal. A adoção de políticas anticíclicas como resposta à crise de 2008 expande e torna mais complexa a natureza desses processos. Movimentos contraditórios, pautados no avanço de instrumentos regulatórios e financeiros sofisticados, articulados à intensificação da apropriação do fundo público, impulsionaram condições excepcionais de acumulação, resultante do porte das obras e das novas possibilidades de captura de renda. Na compreensão das condições particulares engendradas nesse momento, destacam-se o papel histórico do Banco Nacional de Desenvolvimento Econômico e Social (BNDES) na condução dos processos de privatização, a forte ampliação dos financiamentos nesse contexto particular e o crescente poder econômico e político das grandes empreiteiras nacionais.

\footnotetext{
${ }^{1}$ Este artigo é desenvolvido como parte das pesquisas: 1-) “Quando as empreiteiras tornam-se incorporadoras: produção imobiliária e de infraestruturas na transformação da metrópole de São Paulo do século XXI” (Universal Cnpq - 2017- 2021) Processo 426963/2016-4 e 2-) Projeto de pesquisa Fapesp - Imobiliário e Infraestruturas sob domínio de Grandes Grupos Econômicos: Financeirização e metropolização do espaço na São Paulo do Século XXI - Processo no 19/18881-0.
} 
O domínio das grandes empreiteiras nacionais, ainda que se configure como uma particularidade, torna o caso brasileiro paradigmático para o debate dos processos de privatização e financeirização das infraestruturas por nos permitir compreender com clareza como o crescente controle de poderosos agentes privados sobre o setor tem impulsionando novas possibilidades e patamares de acumulação, por meio da crescente centralidade de mecanismos rentistas. Nesse sentido, nosso artigo contribui para o aprofundamento da discussão teórica sobre a financeirização e sua inerente conexão com a expansão de lógicas rentistas.

Partindo de um diálogo com o debate internacional sobre os processos de privatização e financeirização das infraestruturas, com destaque às dinâmicas posteriores à grande crise financeira mundial, procuramos compreender as transformações na produção e operação de infraestruturas no Brasil, analisando os arranjos institucionais, agentes dominantes e as estratégias de acumulação mobilizadas. 0 artigo desenvolve-se considerando um esforço de mediação entre a discussão teórica e a investigação empírica. A problematização teórica parte de revisão bibliográfica sobre os processos de privatização e financeirização, produzidos de maneira dominante no contexto dos países centrais. A investigação empírica, focada no caso brasileiro, sustenta-se na interpretação crítica e articulada do avanço dos instrumentos jurídicos e financeiros e dos papéis desempenhados pelo BNDES e pelas grandes empreiteiras na transformação das lógicas de acumulação no setor. Essa interpretação desenvolve-se por meio de sistematização documental, bibliográfica e de dados secundários. Foram consultados documentos e sites das instituições ligadas ao tema, legislações mais relevantes e bibliografias com análises críticas sobre as transformações analisadas. Além disso, se procurou levantar informações sobre os investimentos do setor, a implementação dos instrumentos de parceria público-privadas e os principais projetos a partir da consulta aos bancos de dados disponibilizados pelo BNDES, Banco Mundial e Radar das PPPs.

0 artigo se estrutura em três partes principais, para além desta introdução e das considerações finais. Na primeira, discutimos a privatização e a financeirização das infraestruturas como processo global, a fim de compreender a articulação entre esses processos e seus desdobramentos no contexto posterior à crise financeira mundial de 2008. Na segunda parte, recuperamos brevemente a inserção do projeto de privatização de infraestrutura no Brasil, discutindo arranjos institucionais, agentes e suas estratégias ao longo dos anos 1990 e 2000. Por fim, na terceira parte, nos focamos sobre a análise da expansão da produção de infraestrutura após 2008, com a discussão da consolidação de um novo patamar de acumulação no setor de infraestrutura, engendrada pela mobilização dos marcos regulatórios e dos instrumentos financeiros sob o comando das grandes empreiteiras.

\section{Privatização e financeirização das infraestruturas como processo global}

A análise sobre a produção e operação de infraestrutura nos países desenvolvidos mostra sua consagração como objeto público em meados do século XX. Nesse contexto, planejamento, financiamento e operação bem-sucedidos eram provas do desenvolvimento e importância do Estado Moderno (O'Neill, 2017, p. 171). Pode-se falar de um amplo consenso social sobre a centralidade da intervenção pública na consolidação da infraestrutura como condição geral aos processos de produção e reprodução social. Tal consenso suportava a infraestrutura como principal área de investimento dos Estados (O’Neill, 2017, p. 172).

0 reconhecimento dessa forma de provisão de infraestrutura, ainda que determinante na sustentação da expansão capitalista, é progressivamente desmantelada. A quebra do consenso emerge nos anos 1980, articulando-se a transformações radicais no capitalismo que trarão implicações imediatas à produção e à operação das infraestruturas (O'Neill, 2017, p. 176).

Especialmente a partir da década de 1990, as ideias neoliberais tiveram um profundo efeito sobre a legitimação das políticas de privatização das infraestruturas, com papel do setor privado também se ampliando no sul global. A privatização de vários ramos da infraestrutura se tornou prescrição recorrente 
por parte de instituições financeiras internacionais sob a forma de Programas de Ajuste Estrutural nos anos 1980 e 1990 (Loftus et al., 2019).

A ascensão do receituário neoliberal e das ideias de privatização pavimentaram a importância crescente das infraestruturas como setor econômico de acumulação capitalista global ${ }^{2}$. 0 Estado, assumindo predominantemente a função regulatória, passou a assegurar, a partir da privatização de seus ativos subvalorizados, ganhos extraordinários a agentes privados, garantindo ainda a constituição de monopólios, oligopólios e garantias tarifárias (Pírez, 1999).

Os estudos sobre o avanço da privatização das infraestruturas vão indicar importantes mudanças nesse processo na virada do século XX para o XXI, suportadas sobretudo por uma crescente articulação do setor ao mercado de capitais, levando o debate da financeirização para o centro das discussões da produção e operação das infraestruturas (Loftus et al., 2019). Karen Bakker (2003 apud Purcell et al., 2019) chama atenção para equívocos que a utilização generalizada do termo privatização pode levar, correspondendo em muitos casos a estratégias distintas e em alguns casos sobrepostas, indo desde a alienação total do bem a diversas formas de Parcerias Público-Privadas. Cada uma dessas estratégias resulta de dinâmicas políticas e econômicas específicas, trazendo implicações distintas, em termos da propriedade dos ativos, possibilidades de acumulação e transformações ao espaço urbano.

Para O’Neill (2019), até o fim do século XX, a lógica de privatização das infraestruturas estava baseada em cálculos simples, suportados pelo rendimento constante advindo do consumo obrigatório de prestadores de serviço que detinham o monopólio (O’Neill, 2019, p. 1306). Nos anos 2000, o aumento da atratividade dos negócios de infraestrutura esteve relacionado à crescente securitização do pagamento de tarifas pelos usuários, gerando produtos financeiros baseados nos contratos de prestação de serviços (O’Neill, 2019, p. 1306). Sob essa nova racionalidade, as estratégias financeiras se tornaram mais relevantes para os ganhos da empresa do que o fornecimento dos serviços. Nesse estágio, a securitização de fluxos de receitas garantidos com a prestação dos serviços passa a ser vendida como mercadoria financeira em uma variedade de arranjos e estratégias de empacotamento. Segundo O’Neill (2019), com o avanço da "liquefação" dos ativos, a performance do setor passou a depender menos dos processos urbanos que geravam fluxos de receita, ou aumento do valor dos ativos e mais sobre as qualidades dos ganhos previstos comparados (por meio de indicadores financeiros) às classes de ativos concorrentes.

Nesse processo, um conjunto de agentes financeiros, presentes desde o início das políticas de privatização, assumem papéis cada vez mais relevantes. Para Lorrain (2011), as finanças globais passam a deter enormes poderes sobre o setor, controlando os processos e as métricas e sendo responsável pela avaliação dos ativos, cálculos de rendimentos e estimativas riscos. Ao articular riscos e retornos, direciona os investimentos desde o início. Essa percepção se tornou relevante para a discussão das transformações com a crise de 2008. Para O'Neill (2017), a ampliação das transformações após 2008 fazem com que o setor de infraestrutura se constitua como uma classe consolidada de investimentos, organizada por grandes instituições financeiras e corporações globais. Pode-se afirmar que, no contexto de crise prolongada e de sofisticação dos instrumentos financeiros relacionados à produção e à operação de infraestruturas, estas têm se consolidado como um dos lugares cruciais de investimento para o capital acumulado excedente nas últimas duas décadas.

A crise financeira internacional, ao mesmo tempo que revelou a dimensão e o poder das finanças na produção e operação de infraestrutura (Lorrain, 2011), engendrou mudanças na forma de atuação dos agentes financeiros, que passaram a priorizar a posse direta de terras e infraestrutura urbana para a extração de renda em detrimento do empréstimo de capital (Purcell et al., 2019).

\footnotetext{
2 Embora não seja objeto desse artigo, cabe ressaltar o grande protagonismo de agentes privados na produção de infraestruturas e sua feição global no século XIX e parte do século XX. Um caso paradigmático da expressão global desses agentes foi discutido por Seabra (1987) para o caso de São Paulo. Ao estudar o processo de retificação do Rio Pinheiros, a autora revelou a centralidade da Ligh\&Co. (Companhia Inglesa) na produção das infraestruturas e os sofisticados mecanismos de acumulação mobilizados pela empresa.
} 
É a partir da análise dessas novas dinâmicas que Purcell et al. (2019) identificam a financeirização como uma nova etapa que se sobrepõe aos processos de privatização. Para Purcell et al. (2019), se o processo inicial de mudança nas infraestruturas aponta para a privatização das propriedades antes operadas pelo poder público, permitindo a extração de renda pela detenção de seu monopólio, o que parece sustentar o avanço das lógicas financeiras é a diversificação de formas de captura de renda originadas em fluxos de receita, cada vez mais empacotados como títulos financeiros - vendidos na forma de capital fictício. Os autores argumentam (Purcell et al., 2019) que a compreensão dessas novas estratégias de acumulação, mais evidentes após a crise de 2008, exige uma interpretação na qual valor, renda e capital financeiro sejam vistos como fortemente entrelaçados, revelando as implicações políticas e econômicas desses processos, bem como os interesses de classes subjacentes. Com essa percepção, os autores indicam que os superlucros realizados pelas concessionárias de infraestrutura são possíveis pelo menos em parte pela captura de diferentes formas de renda, oriundas da propriedade monopolista das infraestruturas.

\section{Da privatização às Parcerias Público-Privadas: transformação dos agentes e das estratégias de acumulação (1990-2007)}

Comparado a muitos países latino-americanos, pode-se verificar o caráter tardio do neoliberalismo brasileiro, ampliado apenas no começo dos anos de 1990, com o governo Fernando Collor de Melo (19901992) em articulação complexa com o processo de redemocratização. Com base nas prerrogativas liberais do Consenso de Washington (1989), tomou força no Brasil a legitimação da ideologia do Estado mínimo e da alegação da ineficiência de suas instituições públicas na coordenação e intervenção econômica, em adesão ao projeto de globalização (Werner, 2019). A partir daí, com o agravamento da crise financeira e cambial herdada da década de 1980, acelera-se o processo de liberalização e desregulamentação financeira, que permitiria atrair montantes consideráveis de capital financeiro especulativo internacional no âmbito de uma grave instabilidade macroeconômica e política. Com a criação do Programa Nacional de Desestatização (PND) por meio da Lei n. 8.031/1990 (Brasil, 1990), a privatização tornou-se parte integrante das reformas econômicas, causando inicialmente vendas de estatais produtivas dos setores siderúrgico, petroquímico e de fertilizantes.

Nos governos de Fernando Henrique Cardoso (FHC) (1995-2002), com alcance de maior estabilidade econômica, a reestruturação econômica avançou com o reforço da priorização das políticas de privatização. Nesse contexto, o PND foi estendido à concessão de serviços públicos e apoio às privatizações no âmbito dos estados da federação. 0 fim dos monopólios públicos e a criação das leis de concessões foram mudanças que impulsionaram a privatização de bens constitucionalmente públicos (Rocha \& Silveira, 2015), marcando o grande comprometimento de FHC com esse projeto. A Lei de Concessões n. 9.879/1995 (Brasil, 1995), marco fundamental para a privatização do setor, regulamentou o artigo 175 da Constituição Federal, autorizando concessionárias privadas a operar serviços públicos. Por meio dela foram estabelecidas regras para a exploração de serviços públicos pelo setor privado, abrindo caminho para um processo de maciça venda das empresas públicas de infraestrutura e concessão dos serviços (Araújo, 2006, p. 172).

Ferreira \& Azzoni (2011) mostram que entre 1995 e 2002 as privatizações de empresas do setor de infraestrutura no Brasil ocuparam um volume significativo, correspondendo a $42 \%$ do volume mundial.

A ascensão do governo dos trabalhadores (2003-2015) traz importantes transformações para a produção e operação das infraestruturas. Embora não haja rompimento com práticas neoliberais, verificase uma reorientação estratégica em direção à maior atuação do setor público na infraestrutura, com maiores intervenções por meio do planejamento, de investimentos e financiamentos (Ferreira \& Azzoni, 2011, p. 49).

No entanto, articulado a novos regulamentos, verifica-se uma relevante expansão da participação privada por meio das PPP - instrumento central na provisão de novas infraestruturas. A lei das PPP (n. 11.079), aprovada em 2004 (Brasil, 2004), é reconhecida como marco das transformações das relações no setor, regulamentando novas possibilidades de concessão pública de obras e serviços pelo fato de o ente 
público poder oferecer contraprestações como forma de complementar o pagamento ao parceiro privado na gestão dos projetos. Essa lei representou um importante passo na extensão de processos de privatização para segmentos antes vistos como não lucrativos, como saneamento, saúde, habitação e rodovias (Rufino, 2016) e para áreas urbanas.

Visualizava-se com a implementação da legislação a ampliação da atração de investimentos privados como estratégia para alavancar a provisão de novos serviços e infraestruturas, considerando simultaneamente construção, gestão e manutenção com validade de operação compatível à amortização dos investimentos feitos, num limite de 30 anos (Rufino, 2016). Prevendo dois modelos contratuais concessão administrativa e concessão patrocinada - a lei procurou responder também às demandas por mais garantias do Estado, por meio da consolidação de fundos garantidores e maior flexibilização na repartição dos riscos decorrentes de novas formas da implementação e gestão dos projetos (De Oliveira Lima, 2014). Por essa lei, os projetos de infraestrutura passaram a ser obrigatoriamente desenvolvidos através da consolidação de Sociedades de Propósito Específico (SPE) ${ }^{3}$, que podem ter ações negociadas em bolsa de valores e emitir títulos financeiros do tipo debêntures ${ }^{4}$ como formas de capitalização mais sofisticadas diretamente associadas aos projetos

Apesar da promessa de produção de novas infraestruturas, o processo de concessão e modernização de infraestruturas pré-existentes permanecerá dominante ${ }^{5}$.

Se as mudanças dos arranjos institucionais apontam para transformações na virada dos anos 1990, cabe observar crescente centralidade do BNDES e das grandes empreiteiras nacionais em todo processo.

Apesar do avanço neoliberal da década de 1990 ter atingido também o sistema financeiro, com marcante entrada de capital estrangeiro por meio de fusões e aquisições de instituições privadas e privatizações de bancos públicos estaduais, um caminho diferente foi delineado para os bancos de propriedade do Governo Federal, como o BNDES, que continuou a desempenhar um papel crucial no sistema financeiro (Mendonça, 2015).

O banco criado nos anos 1950 teve historicamente um importante papel no financiamento de infraestruturas, ampliando sua relevância nos últimos 30 anos (Barboza et al., 2019). Por um lado, essa ampliação do papel do BNDES pode ser explicada por sua responsabilidade em gerir o fundo de poupança compulsória criado em 1990 - o Fundo de Amparo ao Trabalhador (FAT), que se tornou importante fonte dos financiamentos subsidiados do banco. Por outro lado, articula-se ao seu protagonismo nos processos de privatização. Para Farias (2008, p. 70), a experiência pioneira na privatização de empresas que pertenciam ao banco nos anos 1980 serviu de base institucional para as privatizações dos anos 1990. De maneira geral, os procedimentos de privatização utilizados pelo banco nos anos 1980 - vendas em leilões públicos na bolsa de valores, precificação dos ativos por consultorias internacionais e supervisão do processo por auditoria independente - foram adotados no PND, no qual coube ao BNDES atuar como gestor do fundo.

Farias (2008) destaca que o banco, em sua "nova" função burocrática de conduzir processos de privatização, promoveu uma significativa articulação entre a burocracia estatal e a lógica dos mercados, por meio da atuação de empresas transnacionais de consultoria entre outros agentes hegemônicos do período contemporâneo. Em seu trabalho, o autor mostra a participação de consultorias transnacionais, como KPMG, Ernst \& Young, Booz Allen \& Hamilton, PricewaterhouseCoopers e Delloitte nos processos de privatização.

No início do século XXI, diretamente articulado ao crescimento econômico do país, o banco ampliou sua capacidade institucional ao envolver-se na promoção do novo marco regulatório das PPP e na continuada

\footnotetext{
${ }^{3}$ A Sociedade de Propósito Específico (SPE) é um modelo de organização empresarial pelo qual se constitui uma nova empresa, limitada ou sociedade anônima, com um objetivo específico. Representa uma redução de riscos nos negócios, por separar financeira e jurídica o empreendimento (uma concessão de infraestrutura, por exemplo) da estrutura de uma grande companhia.

${ }^{4}$ De acordo com a Comissão de Valores Mobiliários (CVM), a debênture é um valor mobiliário emitido por sociedades por ações, representativo de dívida, que assegura a seus detentores o direito de crédito contra a companhia emissora. Consiste em um instrumento de captação de recursos no mercado de capitais, que as empresas utilizam para financiar seus projetos. 5 De acordo com as informações do banco de dados do Banco Mundial (https://ppi.worldbank.org/en/ppi).
} 
disseminação das concessões comuns. O BNDES passou a assumir a centralidade também na estruturação dos projetos e no desenho dos instrumentos financeiros, que procuravam promover a aproximação entre os empreendimentos (projetos) e o mercado de capitais. Sua atuação na promoção de novos instrumentos de financiamento é compreendida por nós como aspecto central para impulsionar lógicas mais sofisticadas de acumulação na produção e operação de infraestruturas.

Em 2008, em forte articulação com bancos multilaterais internacionais, o BNDES consolidou sua Área de Estruturação de Projetos (AEP), com o objetivo de identificar, fomentar, apoiar e realizar a estruturação de concessões públicas e PPP. A forte disseminação do discurso de ampliação da participação de financiamentos, articulado ao mercado de capitais, se confronta aparentemente com a permanente centralidade do Banco em financiar as infraestruturas para esses agentes. Característica que será fortalecida no enfrentamento da crise financeira mundial.

As políticas de privatização e de expansão das PPP também serão determinantes no aumento do poder das grandes empreiteiras nacionais.

Apesar da expressiva redução de investimentos em infraestruturas nos anos 1980 no Brasil e do fim da proteção do mercado para as empreiteiras nacionais nos anos 1990 (Campos, 2019), as grandes empreiteiras foram duplamente favorecidas pelo avanço das políticas neoliberais e a abertura de mercados, beneficiando-se dos processos de privatização e das políticas de internacionalização implementadas pelo Estado brasileiro nesse período. As pressões internacionais por ampliação da abertura do mercado obrigaram o Estado e as empreiteiras brasileiras a competir e internacionalizar-se, pondo ênfase na diplomacia econômica e em políticas expansivas regionais através da projeção da engenharia brasileira no exterior (Durand, 2018).

Representando um setor de destaque na evolução do grande capital brasileiro (Rocha, 2013), essas serão fortemente beneficiadas pelas políticas de financiamento do BNDES, que também apoiarão seu processo de internacionalização, particularmente na América Latina.

Ao longo da primeira década do século XXI, diretamente articulado à bonança exportadora da América Latina e ao crescimento de investimentos em infraestrutura em todo o continente, essas empreiteiras transformaram-se em poderosas holdings internacionais atuantes em diversos setores da economia, sem perder o controle sobre das grandes obras públicas.

Por meio do controle de importante parcela das concessões e das PPP, as grandes empreiteiras nacionais, que historicamente tiveram um papel determinante na construção de infraestrutura (Campos, 2014), passaram a desempenhar um papel-chave também na operação, atuando em diversos segmentos, inclusive por meio da constituição de novas empresas de concessão específicas em setores como transporte, saneamento e aeroportos (Rufino et al., 2021).

\section{Expansão das infraestruturas como estratégia anticíclica: financeirização e rentismo no pós-crise de 2008}

Ainda que os impactos da crise de 2008 no Brasil tenham sido inicialmente avaliados como uma "marolinha", as análises sobre seus efeitos demonstraram enorme vulnerabilidade e subordinação do país em relação ao capital financeiro e ao comportamento das economias centrais, particularmente dos Estados Unidos. A crise implicou forte queda dos preços das commodities, retração da demanda internacional, redução significativa do fluxo de capital estrangeiro, alta desvalorização do real frente ao dólar e substancial (Marques \& Nakatani, 2011) e acentuado decréscimo do produto interno bruto (PIB), que só voltaria a crescer no segundo trimestre de 2009, apoiado por um conjunto de medidas emergenciais (Marques \& Nakatani, 2011). Entre as medidas emergenciais que visavam conferir liquidez ao sistema financeiro e evitar uma contração maior do crédito, ganharam grande destaque o forte incremento das linhas de créditos dos bancos públicos - que assumiram papel crescente na economia (Carvalho, 2018) e contrabalancearam em certa medida a retração do crédito não estatal. Entre 2008 e 2009, a participação dos bancos estatais Banco Nacional de Desenvolvimento Econômico e Social (BNDES), Caixa Econômica Federal (CEF) e Banco 
do Brasil (BB) - foi ampliada de 36,3\% a 41,5\% (Marques \& Nakatani, 2011). Parte importante do crédito foi mobilizada para viabilizar políticas anticíclicas a partir da dinamização do setor da construção, considerando tanto a expansão da produção habitacional quanto a produção de infraestruturas.

No caso das infraestruturas, evidencia-se um importante incremento de investimentos por meio do PAC. O programa procurou organizar um conjunto de estímulos ao crédito e ao financiamento, melhoria do ambiente de negócios, aprimoramento da gestão, apoiando-se ainda em forte desoneração tributária (Brasil, 2015). Entre 2007 e 2014, os investimentos no setor se elevaram de forma substancial, apresentando um aumento nominal de 167\%, com expansão de investimentos em praticamente todos os segmentos de infraestrutura (Frischtak \& Noronha, 2016, p. 16). A ampliação dos investimentos por meio do PAC correspondeu também a uma concentração de poder na Casa Civil, esvaziando as iniciativas progressistas que vinham sendo desenvolvidas no âmbito do Ministério das Cidades (Maricato, 2017), e direcionando o tratamento das infraestruturas como questão econômica.

Ainda que o PAC tenha sido lançado em 2007, o contexto da crise impulsionou seu reescalonamento, com significativa ampliação dos investimentos. Com o encerramento da primeira etapa do programa (PAC 1 - 2007-2010), foi proposta a segunda etapa (PAC 2 - 2010-2014), na qual se ampliaram os investimentos e a participação de agentes privados. Os investimentos totais nas duas etapas no programa chegaram a mais de 1,5 trilhão de reais, incluindo aí também os investimentos do Programa Minha Casa Minha Vida, que passaram a ser considerados parte do programa a partir de 2014 (Brasil, 2015).

A crise de 2008 aprofundou inicialmente as históricas dificuldades de acesso ao crédito de longo prazo, dando centralidade ao fundo público na aceleração da implementação de infraestruturas por empresas privadas. As infraestruturas entendidas como "gastos produtivos" (Harvey, 2013) e o contexto de crise urbana aprofundado contraditoriamente pelo crescimento econômico deram mais legitimidade a esses investimentos. Com a retomada nos investimentos, a participação privada na implantação e operação de infraestruturas passava a ser uma bandeira de governo, deixando de ser uma questão ideológica para ser apenas uma técnica para aumento de eficiência e velocidade na implantação e gestão das infraestruturas (Sabença, 2018, p. 56).

Com o PAC e o incremento dos investimentos, verificou-se uma forte disseminação das PPP. Segundo o Radar das PPP6, da assinatura do primeiro contrato de PPP em 2006 até 2009 foram contratados 16 projetos, com uma importante aceleração a partir daí. Entre 2010 e 2014, foram assinados outros 56 projetos, sendo que 48 se enquadraram na modalidade administrativa, na qual a sustentação financeira do projeto está fortemente apoiada em contraprestações públicas. Um conjunto de sucessivas alterações na lei, no sentido de ampliar a atratividade de investidores privados, é parte relevante da explicação dessa disseminação.

Se, no contexto imediato à crise, os fundos de pensão vinculados a empresas públicas foram a principal alternativa de financiamento aos projetos de infraestrutura (Jardim e Silva, 2015), a partir de 2009, o BNDES se consagra como principal fonte para os investidores privados. Segundo dados do próprio banco, houve um salto dos financiamentos de infraestrutura de cerca de 39 bilhões de reais em 2008, para 91,4 bilhões de reais em 2009. Dos recursos emprestados pelo banco entre 2007 e 2015, 81\% do valor total foi destinado a empresas privadas (ver Figura 1), com enorme preponderância daquelas de grande porte (ver Figura 2). As baixas taxas de juros de longo prazo (TJLP) foram um diferencial dos empréstimos fornecidos pelo banco.

As curvas dos desembolsos dos financiamentos em infraestrutura pelo BNDES guardam grande relação com os dados apresentados pelo Banco Mundial, relativos ao total dos investimentos de infraestrutura no Brasil com pelo menos $20 \%$ de investimento privado (ver Figura 3). Tal semelhança assenta-se em importante característica do mercado de infraestrutura brasileiro, baseada em uma participação do BNDES em média de $75 \%$ dos financiamentos aos investidores privados.

${ }^{6} 0$ Radar das PPPs é uma consultoria privada especializada na organização da informação pública disponível sobre o mercado nacional de PPPs e concessões. 


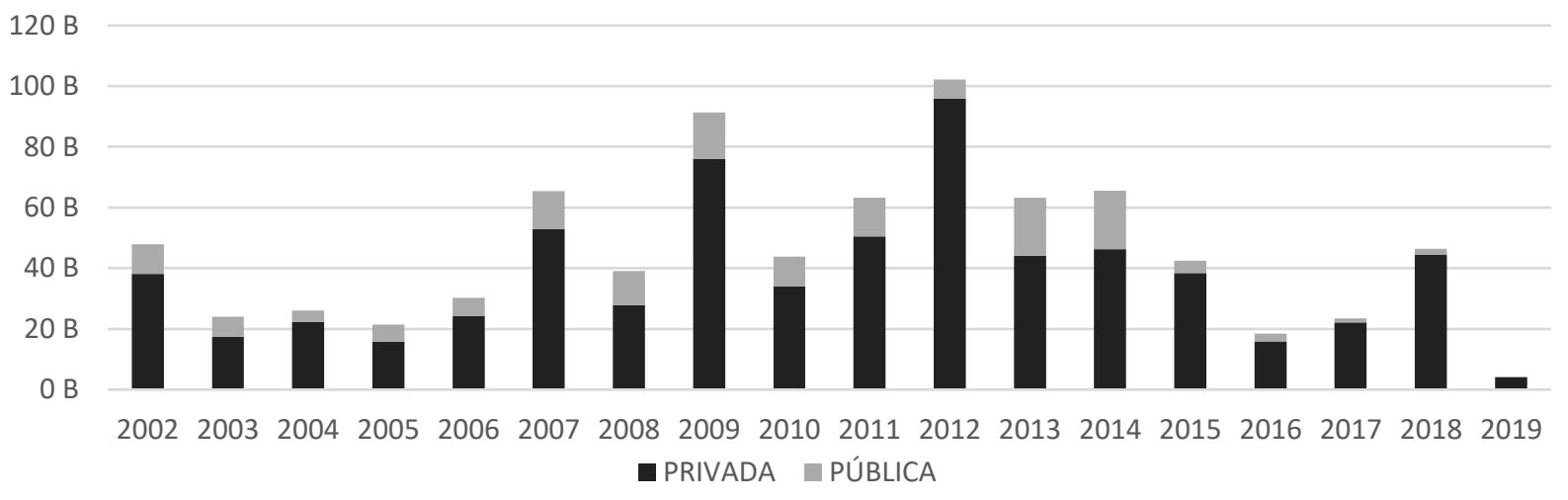

Figura 1 - Desembolsos BNDES na área de infraestrutura em bilhões de reais entre empresas privadas e instituições públicas. Fonte: BNDES.

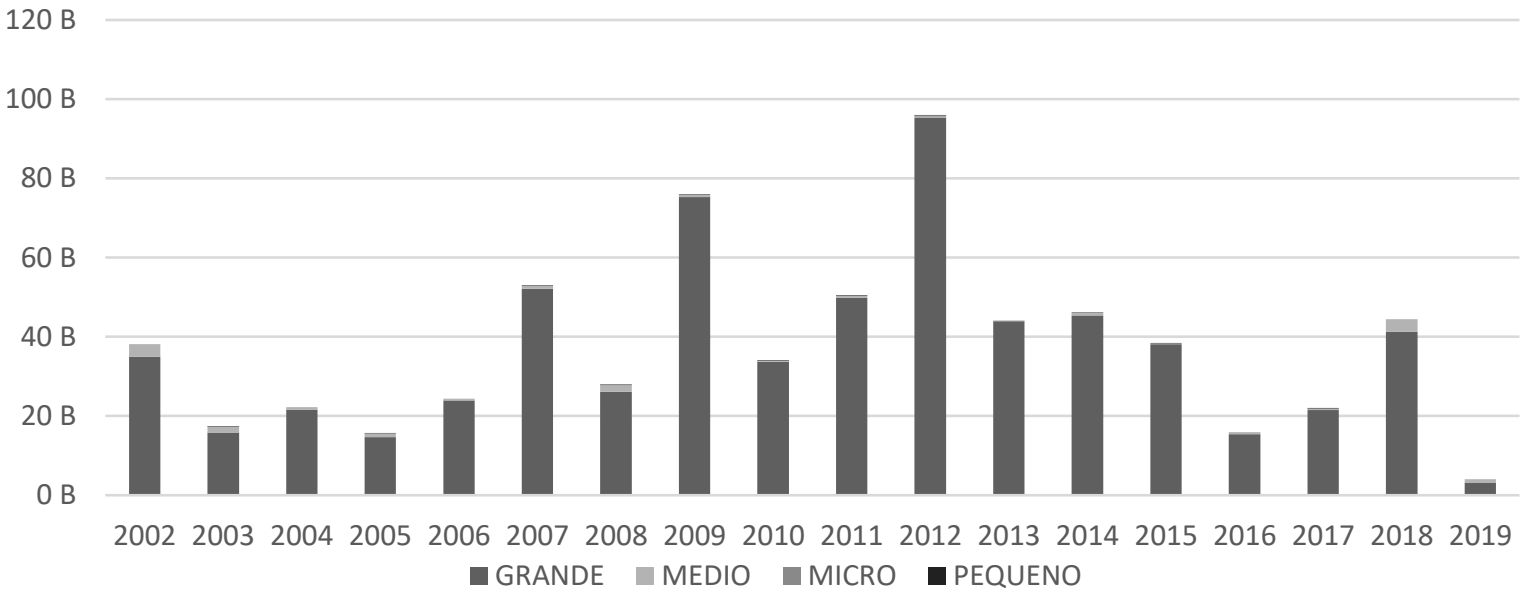

Figura 2 - Desembolsos do BNDES em infraestrutura em bilhões de reais por porte dos clientes. Fonte: BNDES.

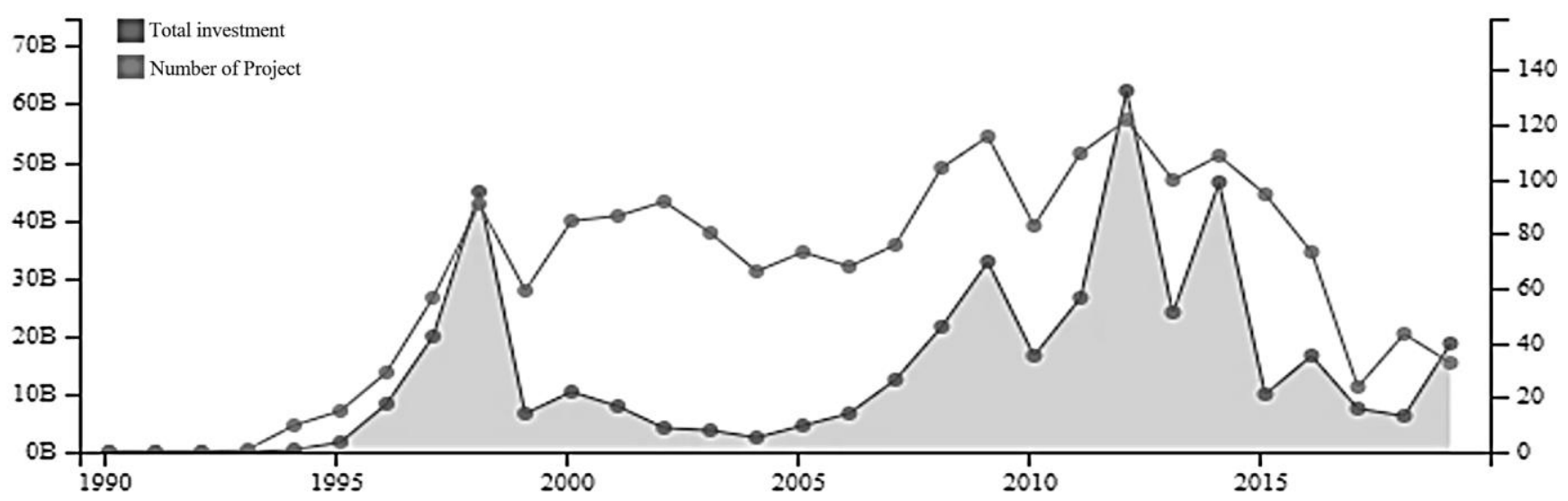

Figura 3 - Investimentos totais em projetos de infraestrutura (em bilhões de US\$) com pelo menos $20 \%$ de investimentos privados. Fonte: Banco Mundial (PPI Project Data Base).

Além de importante fornecedor de financiamento, o BNDES, através do BNDESPAR - braço de investimentos do banco - , passou a deter participação em importantes empresas de concessão, consolidando-se ainda como principal comprador de debêntures, fomentando a construção do mercado de títulos financeiros lastreado nas dívidas das empresas e de seus projetos.

Articuladas ao forte crescimento do mercado financeiro no país, as debêntures tornaram-se progressivamente um instrumento de financiamento com alguma importância aos negócios de infraestrutura. Como mostra Bragança et al. (2015), entre 2007 e 2013, o crescimento do mercado de debêntures foi maior que o de outros ativos dos mercados de capitais, passando de $13 \%$ em 2007 para $50 \%$ 
de todos os ativos no mercado de capitais em 2013. Nesse mesmo período, as empresas de infraestrutura ampliaram sua importância nesse mercado, passando de 16\% do total das debêntures emitidas em 2005 para 54\% em 2013. A partir de 2011, com a Lei n. 12.431 (Brasil, 2011), cria-se a possibilidade de emissão de debêntures em direta articulação com os projetos de infraestrutura, a partir das SPEs, com importantes incentivos tributários para os investidores, como estratégia de disseminar a utilização do instrumento. 0 estímulo ao instrumento reforçará o projeto como unidade de emissão de títulos de dívida, ampliando a disseminação de financiamentos pela modalidade Project Finance.

Embora o Project Finance fosse visto como requisito para maior atração de investidores privados, na prática, a ampliação da expansão dessa modalidade esteve também fortemente relacionada ao aumento dos recursos liberados pelo BNDES em sua linha Project Finance, principalmente nos anos 2009 e 2012 (ver Figura 4). Visando promover a expansão da participação do setor privado em projetos de infraestrutura, o banco aprovou em 2006 a modalidade de financiamento Project Finance, que permite a concessão de crédito a projetos específicos e não mais as empresas. Esse novo instrumento sustenta-se na concepção de projetos de infraestrutura como fluxos de renda, em significativa convergência aos procedimentos utilizados no mercado global de infraestrutura. Como desenvolve Faustino (2019), esse modelo se estrutura a partir do pressuposto de que os próprios retornos advindos do projeto serão responsáveis por remunerar o investidor e honrar os possíveis empréstimos. 0 pilar fundamental dos cálculos é a modelagem econômica, que incorpora o instrumental das finanças aos projetos "como forma de garantir que os investimentos realizados obtenham uma taxa interna de retorno (TIR) compatível com outros investimentos" (Faustino, 2019, p. 3467). Esse modelo de financiamento é apropriado sobretudo para os projetos de grande escala, nos quais seria inviável fornecer garantias reais ou isso comprometeria significativamente a capacidade financeira do tomador (Magalhães, no prelo).

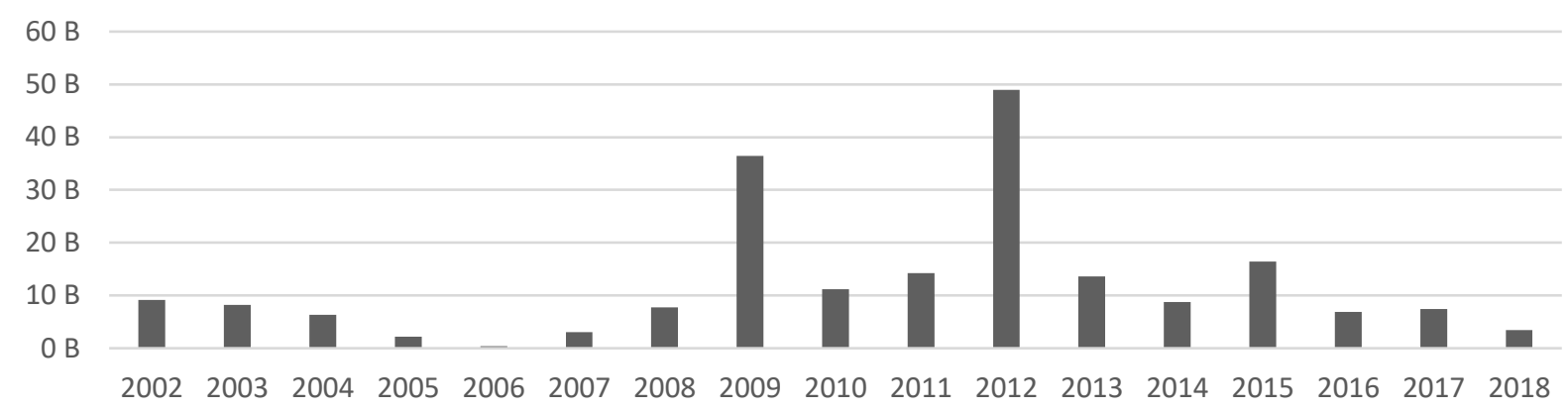

Figura 4 - Financiamentos do BNDES a projetos de infraestrutura na modalidade Project Finance em bilhões de R\$. Fonte: BNDES.

Um aspecto contraditório da atuação "desenvolvimentista" do banco foi sua crescente dependência da emissão de títulos da dívida por parte do governo federal, reforçando um dos canais históricos de penetração de investidores financeiros de curto prazo no país. Como destacam Jardim e Silva (2015), a partir de 2008, o Tesouro Brasileiro passou a captar recursos através de emissão de títulos da dívida pública com mais intensidade, e esses recursos foram repassados sob a forma de financiamento por meio do BNDES para o capital produtivo (PSI) e infraestrutura, com aumento substancial de investimentos, mas com custo financeiro elevado.

Paralelamente à centralidade do BNDES, evidencia-se a consolidação de um novo patamar de acumulação no setor, conduzido pelas grandes empreiteiras e pautado por um conjunto de novas e antigas estratégias de acumulação. Embora tenham se mantido como empresas familiares, tornaram-se integradas às práticas financeiras, tomando a liderança em processos securitização de dívidas e estruturação de projetos.

A internalização de importantes estratégias financeiras permitiu a essas empresas que se inserissem no âmbito global como "investment grade" num contexto de grande crescimento econômico no país, consolidando-se como importantes emissoras de títulos de dívidas em dólar (PwC, 2011). Destacaram-se também pela liderança da modalidade dos contratos do tipo Project Finance, que asseguraram qualificação 
de seus ratings (PwC, 2011). A modernização dessas empresas foi impulsionada em grande medida pela forte parceria estabelecida com o BNDES, renovando em feições modernas os históricos laços das empreiteiras com o Estado brasileiro. Tomando como recorte as empreiteiras com atuação no exterior, Goes e Vilela (2019) verificam que da totalidade dos recursos repassados pelo BNDES para a atuação desse conjunto de empresas no território nacional entre 2002 e 2014 mais de 90\% dos valores financiados foram concentrados em quatro das grandes empreiteiras nacionais - Camargo Corrêa, Odebrecht, Andrade Gutierrez e Queiroz Galvão. Ao se observar os desembolsos do BNDES exclusivos para o caso da Odebrecht (ver Figura 5), verifica-se um substantivo crescimento de financiamento para sua atuação no território nacional, em paralelo à permanência dos repasses à exportação - considerados fundamentais à internacionalização. Em 2013, o banco, por meio do BNDES Participações S.A. (BNDESPar), torna-se ainda acionista da Odebrecht Transportes Participações S.A. (OTP). 0 apoio do banco às empreiteiras, como já mencionado, será também relevante na compra das debêntures emitidas pelas empresas.

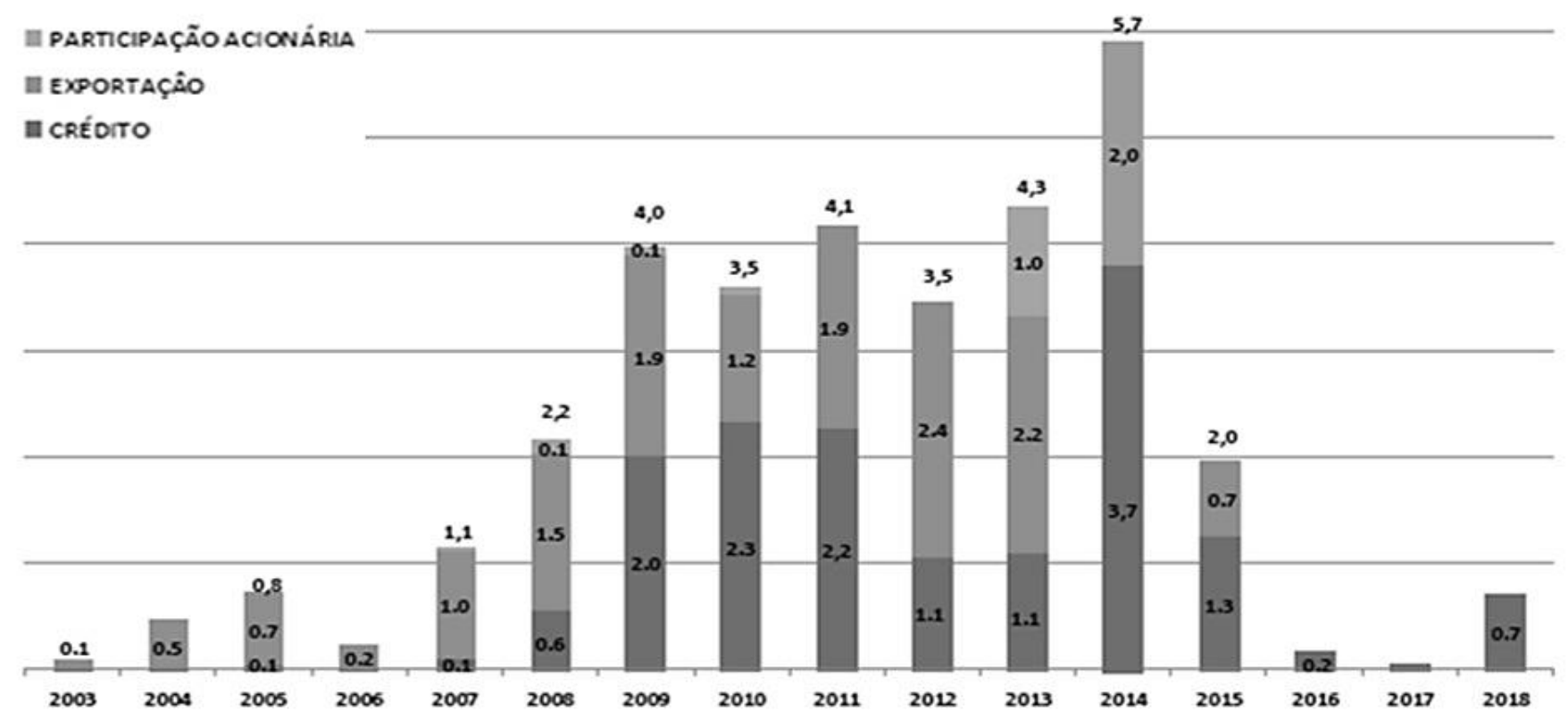

Figura 5 - Desembolsos do BNDES ao Grupo Odebrecht em R\$ bilhões. Fonte: BNDES.

O destaque das grandes empreiteiras nacionais é também identificado na implementação das PPP. Segundo dados do Radar das PPP, dentre todos os projetos de PPP iniciados até 2011, 54\% foram contratos com envolvimento das cinco principais empreiteiras brasileiras, com forte presença da Odebrecht, que está envolvida em $89 \%$ desses contratos de forma direta, mas também indiretamente, através da formação de consórcios estabelecidos para execução dos projetos.

As vantagens obtidas pelas empreiteiras relacionam-se ainda com a ativa participação destas nos Procedimentos de Manifestação de Interesse (PMI). 0 avanço das PPP foi acompanhado, em grande medida, por transformações radicais na concepção das infraestruturas marcadas pelo predomínio de estruturadoras privadas relacionadas às maiores empreiteiras. Nos projetos de maior complexidade, que demandam grande capitalização e especialização técnica, estas ampliaram seu histórico controle sob o setor (Rufino, 2016), constituindo um verdadeiro monopólio dos projetos mais rentáveis de infraestrutura. Além de maior complexidade financeira e escala ampliada, os projetos passam a prever cada vez mais as chamadas receitas alternativas, complementares ou acessórias, derivadas de projetos associados relacionados tangencialmente à execução do contrato de concessão. Dentro dessa racionalidade, o aumento da escala e da complexidade dos projetos tendem a impulsionar os ganhos complementares.

Ao analisar o crescimento exuberante das grandes empreiteiras no período, a partir de seus relatórios anuais, observa-se que os negócios de concessão passaram a representar progressivamente volumes 
maiores dentro das holdings. Os contratos de concessões, ao assegurarem um fluxo de caixa contínuo e de longa duração, irão constituir oportunidades muito mais rentáveis a estas empresas, representando valores financeiros muito maiores do que as margens ou lucros das obras. Há nessa estratégia de reestruturação empresarial uma aposta clara em ganhos rentistas oriundos da exploração de condição de monopólio outorgada pelos contratos de concessão. Essa perspectiva ganhará força no contexto de ampliação dos investimentos no setor de infraestrutura urbana com a sofisticação na concepção e no desenho dos projetos. Esse maior direcionamento ao urbano, coincidiu ainda com a consolidação de empresas de incorporação e de propriedades imobiliárias por parte destes grandes grupos econômicos, que ganharam protagonismo no setor ao concentrarem seus investimentos nos espaços mais valorizados e de reestruturação urbana das metrópoles, beneficiando-se em alguns casos da forte articulação com o desenvolvimento de infraestruturas (Rufino et al., 2021). Os grandes projetos de infraestrutura, que emergem em articulação à forte valorização imobiliária entre 2008 e 2014 e aos grandes eventos, têm em comum a participação das grandes empreiteiras na formação dos consórcios responsáveis pela gestão das SPE e sua concentração nos espaços metropolitanos, dando impulso a acelerados processos reestruturação urbana.

De acordo com dados do Banco Mundial, entre 2008 e 2015, dos dez maiores projetos de infraestruturas desenvolvidos no país, quatro estavam localizados nas metrópoles de São Paulo e Rio de Janeiro. Dentre essas obras, destaque para os aeroportos do Rio de Janeiro e de São Paulo, cujos investimentos, de 10,55 e 9,36 bilhões de dólares respectivamente, eram inferiores apenas ao Projeto da Usina Hidrelétrica de Belo Monte. Constavam também nas sétima e oitava posições as propostas de metrô das duas cidades - Linha Laranja em São Paulo e Linha 4 no Rio de Janeiro. Além do grande porte, esses projetos se particularizam pelos complexos arranjos na concepção financeira e projetual, com forte participação de ganhos complementares associados a negócios imobiliários.

A crítica formulada por agentes mais alinhados ao processo de financeirização é que a predominância da participação das grandes empreiteiras, sócias nas SPE e operadoras dos projetos de PPP, prejudicaria o desempenho geral do projeto enquanto investimento financeiro (Amorim et al., 2015). Segundo os autores, estabelece-se aí uma contradição, dado que ao atuarem simultaneamente na construção e concessão, poderiam privilegiar a maximização dos ganhos nas obras, prejudicando os ganhos da concessão, que tem a redução dos custos de construção como importante estratégia de maximização dos rendimentos de uma operação (Amorim et al., 2015). Essa discussão, restrita a uma preocupação sobre as lógicas de acumulação financeira, pouco avança na compreensão das particularidades do caso brasileiro. 0 protagonismo das grandes empreiteiras e seu enorme poder econômico no controle de instrumentos financeiros e dos maiores projetos de infraestruturas, tomados agora como propriedades, parece iluminar a persistente relevância dos ganhos com a construção, associados a potencialização de enormes ganhos rentistas.

Para Folin (1977), as infraestruturas, como forma especial de capital fixo, se particularizam por se realizar por meio da renda no desenvolvimento das cidades. Historicamente, essa renda foi auferida pelos proprietários de terras a partir da fragmentação do espaço da cidade em propriedades. Com a crescente centralidade da transferência da propriedade de infraestrutura para grandes grupos econômicos, por meio dos novos instrumentos jurídicos e com o suporte da mobilização do fundo público, as possibilidades de captura de renda se avolumam, e fazem com que a infraestrutura em si se torne um importante negócio imobiliário-financeiro, que se associa ainda a outros tipos e fluxos de renda assegurados pelos contratos de operação.

\section{Considerações finais}

A análise das transformações na produção das infraestruturas para o caso brasileiro mostra que, embora a privatização das infraestruturas tenha se constituído nos anos 1990 como uma bandeira dos governos fortemente neoliberais, foi a ampliação dos investimentos no contexto de governos progressistas que possibilitou a aceleração destas dinâmicas, estruturando novos patamares de acumulação no setor. 
Essas transformações são impulsionadas no contexto da crise de 2008 que, ao reforçar a vulnerabilidade econômica do país e impor severas contrações ao crédito, legitimou políticas anticíclicas de dinamização da produção de infraestrutura. A centralidade do BNDES nesse processo expõe as contradições do assim chamado novo desenvolvimentismo. O Banco permanece central na promoção da modernização dos marcos regulatórios da privatização e dos instrumentos financeiros alinhados ao mercado de capitais, ao mesmo tempo em que amplia seu potencial de financiamento, oferecendo condições privilegias aos agentes privados.

O crescente poder econômico e político das grandes empreiteiras sustentado por importante reestruturação empresarial, com forte direcionamento a uma acumulação rentista, realiza-se por meio do controle dos complexos arranjos de financiamento, da captura de fundo público e da condução da sofisticação dos projetos de infraestruturas, em aproximação e conexão com lógicas imobiliárias. Em alinhamento com as discussões de Purcell et al (2019), acreditamos que a novidade para o debate internacional sobre a financeirização aportada a partir do caso brasileiro reside menos em novas formas de produção de valor e acumulação de capital, que muitas vezes são equiparadas ao termo, e mais na ampliação e sofisticação de mecanismos de extração de renda, mediada pelo controle de instrumentos financeiros e da propriedade das infraestruturas formalizadas pelos contratos de concessão. Embora a possibilidade de uma acumulação rentista seja uma forma histórica de repartição da valorização capitalista, e particularmente importante nos países latino-americanos, a ascensão do domínio das finanças abre novas oportunidades e racionalidades na captura da renda. Para Christopher (2019), a financeirização pode ser compreendida como uma vanguarda do rentismo.

0 forte controle das grandes empreiteiras sobre a privatização das infraestruturas, que tem potencializado a centralidade da renda como traço da financeirização, expõe, por outro lado, especificidades do caso brasileiro no qual, até o final de 2014, evidenciava-se reduzida penetração de instituições e corporações financeiras globais, dominantes no contexto internacional.

A ausência dessas instituições não bloqueará o avanço de uma acumulação financeira, imprimindo, entretanto, feições particulares a esse processo. Em nosso contexto, o avanço do binômio privatizaçãofinanceirização é protagonizado, como procurou-se demonstrar, por forte captura de condições privilegiadas de financiamentos e instrumentos financeiros, organizados pelo Estado, como base da concepção de rentáveis projetos. Dada a vulnerabilidade de nossa economia e os interesses de curto prazo do capital financeiro internacional no investimento nos países periféricos, o fundo público é justificado como estratégia de pavimentação do amadurecimento de instrumentos financeiros e jurídicos que suportam os processos de financeirização, construídos em importante sintonia com a modernização dos grupos econômicos nacionais.

Ainda que a articulação com os mercados de capitais seja deficiente, em comparação às estruturas e práticas identificadas no norte global, a lógica de priorização de projetos mais rentáveis de larga escala se impõe, ampliando os processos de diferenciação espacial sem resolver a insuficiência de infraestruturas nos territórios precários. Ao exacerbar as contradições inerentes à financeirização das infraestruturas, o caso brasileiro parece oferecer condições privilegiadas ao desenvolvimento teórico do tema a partir do exame cuidadoso de nossa realidade.

\section{Referências}

Amorim Filho, M. H. D., Leite, L. W. C. \& Chambarelli, M. A. P. P. (2015). Parcerias público-privadas: uma classe de ativos para investimentos. Revista do BNDES, 44, 251-309.

Araújo, W. F. G. (2006). As estatais e as PPPs: o project finance como estratégia de garantia de investimentos em infraestrutura. Revista do Serviço Público, 57(2), 169-190.

Barboza, R. de M., Furtado, M. \& Gabrielli, H. (2019). A atuação histórica do BNDES: o que os dados têm a nos dizer? Brazilian Journal of Political Economy, 39(3), 544-560. https://dx.doi.org/10.1590/0101-35172019-2910 
Bragança, G. G., Pessoa, M. de S. \& Souza, G. M. de. (2015). Evolução recente do mercado de debêntures no Brasil: as debêntures incentivadas. IPEA: Texto para discussão 2158.

Brasil (2015). PAC2: a gente faz um Brasil de oportunidades. Distrito Federal: 11 balanço 2011-2014.

Brasil (1990, 13 de abril). Lei n. 8.031, de 12 de abril de 1990. Cria o Programa Nacional de Desestatização, e dá outras providências. Brasília: Divisão de Orçamentos, Finanças e Contabilidade, p. 7.103.

Brasil (1995, 14 de fevereiro). Lei n. 8.987, de 13 de fevereiro de 1995. Dispõe sobre o regime de concessão e permissão da prestação de serviços públicos previsto no art. 175 da Constituição Federal, e dá outras providências. Brasília: Diário Oficial da União, p. 1917.

Brasil (2004, 31 de dezembro). Lei n. 11.079, de 30 de dezembro de 2004. Institui normas gerais para licitação e contratação de parceria público-privada no âmbito da administração pública. Brasília: Diário Oficial da União, p. 6.

Brasil (2011, 27 de junho). Lei n. 12.431, de 24 de junho de 2011. Dispõe sobre a incidência do imposto sobre a renda nas operações que especifica, [...]. Brasília: Diário Oficial da União, p. 1.

Bresser-Pereira, L. C. (2007). Novo desenvolvimentismo e ortodoxia convencional. In. Globalização, Estado e desenvolvimento: dilemas do Brasil no novo milênio, 20(3), 63-96.

Campos, P. H. P. (2014). Estranhas catedrais: as empreiteiras brasileiras e a ditadura civil-militar, 1964-1988. Rio de Janeiro: FAPERJ/EDUFF.

Campos, P. H. P. (2019). The effects of the economic crisis and the 'Operation Car Wash' inquiry on Brazil's heavy industry: denationalization, bankruptcies and productive disruption. Mediações, 24(1), 127-153.

Carvalho, L. (2018). Valsa brasileira: do boom ao caos econômico. São Paulo: Todavia.

Christophers, B. (2019). The rentierization of the United Kingdom economy. Environment and Planning A: Economy and Space, $0308518 \times 19873007$.

De Oliveira Lima, C. E. D. (2014). Parcerias Público-Privadas: a reforma de 2012 e a possibilidade de pagamento imediato dos aportes financeiros pelo parceiro público. JUS.com.br. Recuperado em 30 de setembro de 2020 de https://jus.com.br/artigos/27176/parcerias-publico-privadas-a-reforma-de-2012-e-a-possibilidade-de-pagamentoimediato-dos-aportes-financeiros-pelo-parceiro-publico.

Durand, F. (2018). Odebrecht: la empresa que capturaba gobiernos. Lima: Fondo Editorial, Pontificia Universidad Católica del Perú.

Farias, H. C. (2008). O BNDES e as privatizações no uso do território brasileiro (Dissertação de mestrado). Instituto de Geociências, Universidade Estadual de Campinas, Campinas.

Faustino, R. B. (2019). Parcerias público-privadas e a financeirização da infraestrutura urbana no brasil. In Anais do XVI Simpósio Nacional de Geografia Urbana XVI SIMPURB (p. 3458-3477). Vitória: UFES.

Ferreira, T. T. \& Azzoni, C. R. (2011). Arranjos institucionais e investimento em infraestrutura no Brasil. Revista do BNDES, Rio de Janeiro, (35), 37-85.

Folin, M. (1977). La ciudad del capital y otros escritos. México: G. Gili.

Frischtak, C. \& Noronha, J. (2016). PAC-Avaliação do Potencial de Impacto Econômico. Brasília: Câmara Brasileira da Indústria da Construção-CBIC.

Goes, F. L. \& Vilela, R. O. (2019). Produção do espaço urbano a partir do apoio público às construtoras nacionais no Brasil. In Anais do XVI Simpósio Nacional de Geografia Urbana-XVI SIMPURB (p. 3320-3336). Vitória: UFES.

Harvey, D. (2013). Os limites do capital. São Paulo: Boitempo.

International Finance Corporation (2016). Estruturação de projetos de PPP e concessão no Brasil: diagnóstico do modelo brasileiro e propostas de aperfeiçoamento. Brasília: International Finance Corporation.

Jardim, M. C. \& Silva, M. R. (2015). Programa de aceleração do crescimento (PAC): neodesenvolvimentismo? São Paulo: Editora Unesp.

Kaltenbrunner, A. \& Painceira, J. P. (2018). Financierización en América Latina: implicancias de la integración financiera subordinada. Estudios sobre financierización en América Latina, 33. 
Loftus, A.; March, H. \& Purcell, T. F. (2019). The political economy of water infrastructure: an introduction to financialization. Wiley Interdisciplinary Reviews: Water, 6(1), 1326.

Lorrain, D. (2011). La main discrète: la finance globale dans la ville. Revue française de science politique, 61(6), 1097-1122. doi:10.3917/rfsp.616.1097.

Magalhães, A. L. C. (no prelo). O modelo muda, os agentes seguem os mesmos? O avanço das PPPs no metrô de São Paulo e as grandes empreiteiras nacionais. In Infraestrutura em disputa. Rio de Janeiro: Letra Capital.

Maricato, E. (2017). O impasse da política urbana no Brasil. São Paulo: Editora Vozes Limitada.

Marques, R. M. \& Nakatani, P. (2011). La crisis mundial y la economía brasileña. Realidad económica, 265.

Mendonça, A. R. R. (2015). Bancos de desenvolvimento e políticas públicas anticíclicas: um estudo de experiências no Brasil e no Chile. In CGEE (org.). Dimensões estratégicas do desenvolvimento brasileiro. (v. 4). Brasil: em busca de um novo modelo de desenvolvimento. Brasília.

Seabra , O. C. de L. (1987) Meandros dos rios nos meandros do poder: Tietê e Pinheiros (Tese de Doutorado). Faculdade de Geografia, Universidade de São Paulo.

O’Neill, P. (2017). Infrastructure's contradictions. In Christophers, B., Leyshon, A. \& Mann, G. (eds.). Money and finance after the crisis: critical thinking for uncertain times. John Wiley \& Sons.

O'Neill, P. (2019). The financialisation of urban infrastructure: a framework of analysis. Urban Studies, 56(7), 1304-1325.

Pírez, P. (1999). Gestión de servicios y calidad urbana en la ciudad de Buenos Aires. EURE, Santiago, 25(76), 125-139.

Purcell, T. F., Loftus, A. \& March, H. (2019). Value-rent-finance. Progress in human geography, 1-20. https://doi.org/10.1177/0309132519838064

PwC. (2011). Crescimento reinventado. Perspectivas nos mercados emergentes alimentam a confiança dos CEOs. Sétima Pesquisa de Líderes Empresariais Brasileiros. PricewaterhouseCoopers Brasil. Recuperado em 10 de outubro de 2020 de https://www.pwc.com.br/pt/ceo-survey-brazil/assets/7a-pesquisa-lideres-11a.pdf

Rocha, M. (2013). Grupos econômicos e capital financeiro: uma história recente do grande capital brasileiro (Tese de doutorado). Instituto de Economia da Universidade Estadual de Campinas, Campinas.

Rocha, M. A. M. \& da Silveira, J. M. F. J. (2015). Propriedade e controle dos setores privatizados no Brasil: uma avaliação da reestruturação societária pós-privatização. Revista de Economia Contemporânea, 19(1).

Rufino, B. (2016). Public-private partnerships and their implications for inclusive urbanisation in Brazil. Regions Magazine, 303(1), 14-15.

Rufino, B., Wehba, C., \& Magalhães, A. L. (2021). Quando empreiteiras tornam-se incorporadoras: um olhar sobre as articulações entre produção imobiliária e de infraestruturas na metrópole de São Paulo do século xxi. EURE (Santiago), 47(140), 159-177.

Sabença, M. R. (2018). As grandes construtoras e a política econômica nos governos Lula e Dilma (Dissertação de mestrado). Instituto de Filosofia e Ciências Humanas da Universidade Estadual de Campinas, Campinas.

Werner, D. (2019). Neoliberalização da infraestrutura: mudanças regulatórias e configuração do setor elétrico brasileiro (1990-2018). Semestre Económico, 22(50), 151-177.

Editor: Paulo Nascimento Neto

Recebido: 30 nov. 2020

Aprovado: 03 mai. 2021 